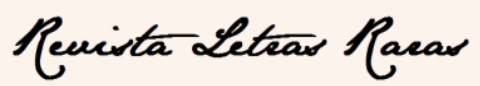

ISSN: $2317-2347$ - v. 8, n. 2 (2019)

\title{
No museu, o Amanhã no entrelaçamento entre história e memória /
}

\author{
In the museum, the Tomorrow in the interweaving between history and \\ memory
}

\author{
Elaine Pereira Daróz* \\ Lucília Maria Abrahão e Sousa ${ }^{* *}$
}

\begin{abstract}
RESUMO
Sob um efeito de evidência, os dizeres/sentidos (re)produzidos ao longo dos tempos, se regularizam numa relação intrínseca entre história e memória. A nosso pensar, ao extrapolarem a linguagem, esses dizeres se materializam nas práticas sociais, produzindo efeitos nos sujeitos discursivos. Filiados na Análise do discurso de linha pecheutiana, propomos neste trabalho uma reflexão sobre os sentidos inscritos no Museu do Amanhã (MA), buscando, nesse gesto, um diálogo com o conceito de Presentismo, fundado pelo historiador Hartog (2011). No estabelecimento da disciplina, Pêcheux se ancorou numa tríplice aliança entre diferentes campos do saber, dentre os quais a História oferece relevante contribuição. Ao propormos esse diálogo, já iniciado por Pêcheux, consideramos que nos fornecerá maiores subsídios para uma desnaturalização desses sentidos, bem como uma melhor compreensão dos seus efeitos na esfera social. Ao longo do nosso trabalho, observamos que afinados com as demandas da atualidade, o MA regulariza uma memória sobre o Brasil, e o brasileiro, com vistas a uma idealização de povo e representação de sociedade.
\end{abstract}

PALAVRAS-CHAVE: Museu do Amanhã; Análise do discurso; Presentismo; Memória; História.

\begin{abstract}
Under an effect of evidence, the words/senses (re)produced over time, become regularized in an intrinsic relation between history and memory. To our thinking, in extrapolating the language, these words materialize in social practices, producing effects in the discursive subjects. On the discursive approach, we propose in this paper a reflection on the meanings inscribed in the Museum of Tomorrow (MT), seeking, in this gesture, a dialogue with the concept of Presentism, founded by the historian Hartog (2011). In the establishment of the discipline, Pêcheux anchored in a triple alliance between different fields of knowledge, among which History offers relevant contribution. In proposing this dialogue, already initiated by Pêcheux, we consider that it will provide us with greater subsidies for a denaturing of these senses, as well as a better understanding of their effects in the social sphere. Throughout this paper, we have observed that, attuned to the demands of today, the MT regulates a memory about Brazil, and the Brazilians, with a view to an idealization of people and representation of society.

KEYWORDS: Museum of Tomorrow; Discourse analysis; Presentism; Memory; History.
\end{abstract}

\section{Introdução}

“Como será o amanhã Responda quem puder

\footnotetext{
* Pós-doutoranda na Faculdade de Filosofia, Ciências e Literatura de Ribeirão Preto da Universidade de São Paulo - FFCLRP/USP, Ribeirão Preto, São Paulo, Brasil, (FAPESP 2018/13017-2), lainedaroz@gmail.com.

** Livre Docência em Ciência da Informação e Documentação na Universidade de São Paulo, Ribeirão Preto, São Paulo, Brasil (FAPESP 2016/22675-8). luciliamsr@uol.com.br.

Todo o conteúdo da Revista Letras Raras está licenciado sob Creative Commons Atribuição 4.0 Internacional
} 


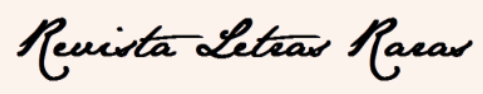

ISSN: $2317-2347$ - v. 8, n. 2 (2019)

O que irá me acontecer

O meu destino será como Deus quiser"

João Sérgio

A relação do homem com a sua história não se dissocia da sua relação com o tempo. Ao longo dos anos, a impotência perante o futuro lhe fez olhar para o passado como o seu fiel escudeiro, a história, sua melhor conselheira, rumo ao progresso. Desde cedo os gregos compreenderam a importância de remontar os fatos, como uma necessidade de preservação de uma memória sobre os povos, suas crenças, da sua história; com vistas à transmissão da herança aos seus descendentes. Por meio de representações sociais, os valores e costumes foram transmitidos num jogo discursivo que implicava deuses e semideuses, criando uma tradição, (re)contada desde os primórdios da civilização ocidental.

Nessa relação, a mitologia grega afirma ser Mnemosyne, a Memória, a dona da sabedoria e guardiã dos tesouros culturais do seu povo. Irmã de Chronos, o Tempo, é também mãe de Musas como Clio, a História. Ao longo dos tempos, História e Memória foram ganhando novos contornos na medida da relação do homem com o tempo, e com a sua história, foi-se transformando (ROSÁRIO, 2002). A partir do século XX, o desenvolvimento científico e tecnológico foi tomando o seu espaço na esfera social, e as transformações sociais proporcionaram novas formas de significação. No século XXI, lidar com o tempo é mais um desafio do homem pós-moderno. O tempo, não mais compreendido de forma cronológica, é significado na sua espacialidade, promovendo um redimensionamento do homem no espaço. O amanhã já não é tão distante, e o futuro parece ser agora. A modernidade líquida comporta outras configurações de tempo e espaço, dadas pelo aporte da tecnologia, da temática, da microbiologia, da genética, e muitas vezes tais configurações colocam o tempo em uma rede de atualizações, repetições e rupturas des-fronteirizadas e diluídas, não se sabendo, por exemplo, se uma imagem é atual ou antiga, se outra diz respeito à ficção ou realidade, se uma palavra é de agora, ontem ou profecia de um depois.

Neste trabalho, buscamos uma reflexão sobre o lugar da memória na regularização dos sentidos diante do objeto nomeado como Museu do Amanhã (MA). Para isso, trazemos um diálogo entre a noção de presentismo de Hartog (2017) e os pressupostos teórico-analíticos da Análise do Discurso de filiação francesa (Pêcheux), 


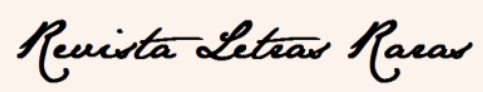

ISSN: $2317-2347$ - v. 8, n. 2 (2019)

tomando em atenção a relação entre a história e a memória, como pilares para a regularização dos sentidos no seio social. Nesse percurso, lançamos um olhar sobre o modo de funcionamento dos sentidos sobre o referido museu, tendo em vista os seus efeitos na regularização de uma memória sobre o Brasil, e o brasileiro, na atualidade.

\section{Clio e Mnemosyne: a relação íntima entre a história e a memória na regularização dos sentidos}

No arcabouço literário da Grécia Antiga o papel da memória se revela na $1^{\text {a }}$ geração de mitos, sob a deusa Mnemosyne, a Memória, significada como mãe de musas como Clio, a História. Numa relação íntima entre Memória e História, a Memória ocupa um relevante papel estrutura social, tendo como algumas de suas funções a seleção de informações que seriam transmitidas (ROSÁRIO, 2002). No século XIX, a História, a magistra vitae, é elevada ao estatuto de Ciência, tendo como uma de suas principais funções a interligação entre passado-presente-futuro. Pautada nessa relação aparentemente evidente de um tempo, os sujeitos eram convocados a repensar suas práticas, quer para melhor se situar no presente, quer para construir novas possibilidades futuras.

Trazendo consigo o cetro da sabedoria, a Memória é, por sua vez, significada como a base fundamental para a relação do homem com o seu tempo. Numa relação aparentemente retilínea entre passado-presente-futuro, de acordo com Vernant (1990), outra atribuição da Memória era convocar o passado no presente, a fim de direcionar as ações futuras. A Memória estava, assim, muitas vezes ligada à aprendizagem acerca das experiências apreendidas no passado, e a sua divinização tinha um caráter utilitário não apenas de imortalizar os acontecimentos sociais, como também o poder de transformar a história ${ }^{1}$. E foi o conjunto de transformações sociais advindas do século XX, uma das responsáveis para uma reconfiguração na relação linear entre passado-presente-futuro. Acerca dos efeitos do fenômeno da mundialização, possibilitado, inclusive, pelos avanços tecno-científicos em escala global, Kleiman e Vieira (2006) afirmam que,

\footnotetext{
${ }^{1}$ Ao trazermos história, ao invés de História, aportamo-nos nos estudos de Hartog (2017) para o sentido de história significado na pós-modernidade, isto é, não mais pensada a partir de uma ciência que reina absoluta, mas uma construção social e em constante transformação, concomitante à relação do homem consigo mesmo e com o mundo que o cerca.

Todo o conteúdo da Revista Letras Raras está licenciado sob Creative Commons Atribuição 4.0 Internacional
} 


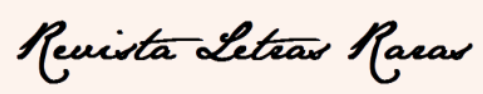

ISSN: $2317-2347$ - v. 8, n. 2 (2019)

[...] o computador oferece-nos novos modelos de mente e um novo meio no qual projeta nossas ideias e fantasias. Mais recentemente, o computador tem se tornado mais do que uma ferramenta e um espelho: nós estamos aprendendo a viver em mundo virtual. Nós podemos descobrirmo-nos sozinhos como se navegássemos em oceanos virtuais. (KLEIMAN; VIEIRA, 2006, p. 9)

$\mathrm{Na}$ atualidade, a utilização dos recursos digitais se tornou a ordem mundial, e alterou até mesmo a forma de pensar e agir dos sujeitos contemporâneos ${ }^{2}$, produzindo novas formas de ser sujeito e subjetividades que se inscrevem a partir de outras condições de produção. A velocidade com que as informações são disponibilizadas e circulam na rede, aliada às inúmeras possibilidades de interlocução e o hiperlabirinto de conexões do ciberespaço, produziu um redimensionamento na relação espaço-temporal do sujeito contemporâneo e, com a ela, a instauração de novas práticas sociais. Um dos efeitos dessas transformações sociais se mostra na alteração na relação hierárquica entre passado-presente-futuro, para uma sobreposição do presente sobre o passado e o futuro, denominada por Hartog (2017) presentismo, como um dos sintomas dessa nova era. Tal conceito nos parece interessante na medida em que dimensiona uma relação contemporânea do homem com o tempo, não mais fazendo culto ao passado, mas inscrevendo-se no presente e no gerúndio de tal maneira e tão afetado pelo arcabouço tecnológico que parece ter controle sobre o agora e o amanhã.

As inúmeras possibilidades, advindas dessa nova era, contribuem para uma multiplicidade de objetos de (e que fazem) a história dos sujeitos, em constante transformação, concomitante à história da humanidade. Nesse deslocamento de sentidos para a História, e para o homem em relação ao seu tempo, a ascensão do presente, e da necessidade de explicações do hoje, traz ao passado, até então pulsante no cotidiano social, uma fina camada de poeira. O amanhã, por sua vez, não é mais distante como parecia outrora, mas bate às portas de sujeitos ávidos não apenas por construir o seu presente, mas, sobretudo, por controlar o seu futuro. Concomitante a atualização da noção de tempo, e da história, a memória também é revisitada. Não mais situada no passado, a memória tem hoje imaginariamente o poder registrar as ações no tempo presente, e apontar os acontecimentos vindouros. Sendo assim, o lugar do museu é ressignificado na nova sociedade, instituindo uma nova forma de regularização de uma

\footnotetext{
${ }^{2}$ Estudos de Oliveira (2010) apontam para as transformações ocorridas nas gerações que cresceram com os recursos digitais presentes em seu cotidiano, em relação às gerações anteriores.

Todo o conteúdo da Revista Letras Raras está licenciado sob Creative Commons Atribuição 4.0 Internacional
} 


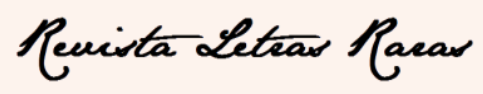

ISSN: $2317-2347$ - v. 8, n. 2 (2019)

memória na esfera social. No caso em questão, estamos diante de um museu que se auto declara "do Amanhã" o que nos parece dialogar com o conceito de presentismo tal como definido anteriormente: o museu de hoje, tecnológico e marcado por uma conexão em/ de redes, teria condições não apenas de desenhar o presente, mas de tomá-lo tão a sério que as verdades de agora passariam também a definir o futuro. Vejamos na sequência deste artigo.

\section{O museu: um lugar de regularização de uma memória}

Na Antiguidade clássica, o mouseion (museu), era o templo onde repousavam as Musas (ROSARIO, 2002), lugar de poesia e oratória onde se debruçavam as artes em suas diversas expressões. Em sua gênese, uma de suas funções era abrigar os mais variados ramos das artes e ciências, como forma de preservação do patrimônio histórico e cultural, atuando, assim, a regularização de uma memória na esfera social (CARLAN, 2008) por meio da evocação do passado. E é a partir do Renascimento que o museu ganha novos contornos e proposições, privilegiando-se, então, o colecionismo privado, financiado por banqueiros e integrantes da burguesia em ascensão.

$\mathrm{Na}$ atualidade, o museu é concebido como uma instituição jurídica, um espaço democrático de percepção crítica da realidade, com o objetivo de propiciar a ampliação do campo de possibilidades de construção identitária, produção de conhecimentos e oportunidades de lazer a serviço da sociedade ${ }^{3}$. Em meio à profusão dos recursos digitais disponíveis, os museus digitais abrem mão dos acervos físicos e passam a funcionar a partir de telas digitais em sua imaterialidade, disponibilizando vídeos, imagens, sons e jogos ao longo de seu espaço, discursivizando efeitos de interação e entretenimento, produzindo efeitos nos seus visitantes sob uma ilusão de evidência de sentidos ali inscritos.

Ao refletir nos sentidos que se regularizam no museu, Romão (2011) afirma que é preciso que se tome em consideração o seu processo de estruturação, tendo em vista a sua dimensão política advinda das relações instituições, visto que são afetados pela subjetividade dos que atuam em sua gestão e organização, o que produz novos gestos de

\footnotetext{
${ }^{3}$ INSTITUTO DO PATRIMÔNIO HISTÓRICO E ARTÍSTICO NACIONAL. Cadastro Nacional de Museus. Disponível em: <portal.iphan.gov.br/files/questionario_cadastro_nacional_de_museus.doc>. Acesso em 6 set 2018.
}

Todo o conteúdo da Revista Letras Raras está licenciado sob Creative Commons Atribuição 4.0 Internacional 


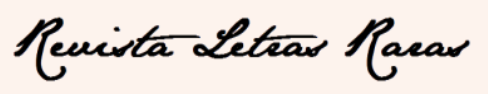

ISSN: $2317-2347$ - v. 8, n. 2 (2019)

leitura do/sobre os arquivos. Sob esse viés, distante de uma acumulação desordenada de arquivos, é inerente ao museu a questão da alteridade, fazendo intervir as antecipações e regras de projeções na relação do sujeito com o outro. Como afirma a autora (ROMÃO, 2011), no interior do museu são supostamente (re)ligados passado, presente e o futuro, obedecendo a uma ordem própria pensada a partir de sua destinação. Constituído por arquivos - físicos ou digitais - previamente selecionados, e meticulosamente dispostos neste espaço, o museu reconta a História dos (e para) sujeitos, convocando um público imaginário a percorrer um caminho (sobre)determinado. Sob esse viés, o museu é inerentemente ideológico, na medida em que nele se marca uma divisão política que se estabelece na luta pela regularização de uma memória do dizer acerca do que pode e deve ser lembrado.

Isto porque, segundo Pêcheux (1988), é no entrecruzamento entre a História e a língua que os sentidos se constituem, visto que acompanha as transformações sociais inerentes a cada tempo, a cada povo. Sendo assim, a língua não é estática e tampouco independente dos acontecimentos históricos inerente à história da humanidade. A História, por sua vez, também não é um recorte caótico e neutro das experiências vividas pelos sujeitos ao longo dos tempos. Numa abordagem discursiva, compreendese que a História é resultante de um gesto analítico tomado a partir de uma posição ideológica pré-determinada, tornando-se o arcabouço de uma disputa de poder acerca dos dizeres/sentidos a serem estabilizados na esfera social. Nesse processo, o papel da memória é preponderante, atuando na de reprodução/circulação dos sentidos a serem regularizados que, condizentes com os interesses da ordem vigente, norteiam as práticas sociais.

Em estudo apresentado no colóquio História e Linguística, Pêcheux (1999) preconiza que os discursos são estruturados numa relação entre memória e atualidade, possibilitando sempre o surgimento do novo. Isso porque, segundo o autor (PÊCHEUX 1999, p.56), a memória é "um espaço móvel de disjunção, de deslocamentos e de retomadas, de conflitos de regularização, um espaço de desdobramentos, réplicas, polêmicas e contra-discursos". Nesses termos, a memória é concebida como uma rede de sentidos que se marcam no fio do discurso por uma reprodução dos sentidos, por meio de retomadas de dizeres/sentidos já-ditos e relativamente estabilizados na esfera 


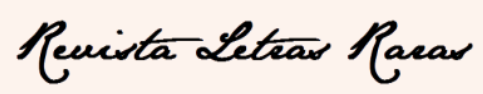

ISSN: $2317-2347$ - v. 8, n. 2 (2019)

social, abrindo brechas para a sua transformação/ atualização, a depender das condições sócio-histórico-ideológicas e das posições dos sujeitos na produção do dizer.

Em especial a partir do século XX, o fenômeno da mundialização, possibilitado, inclusive pelo aperfeiçoamento das tecnologias de informação e comunicação, proporcionou um processo de transformações sócio-político-econômicas em escala mundial, cujos efeitos incidem, inclusive, sobre a relação do sujeito com o tempo, e com a sua história. A velocidade com que as informações circulam na rede, às possibilidades de conexão interpessoais, advindas dos recursos digitais, parece interpelar os sujeitos no aqui e agora, fazendo intervir já no presente os sentidos para o amanhã. O Museu do Amanhã (doravante MA) coloca-se exatamente nesse lugar. Essa é, segundo Hartog (2017), uma das características do presentismo, como um dos efeitos das transformações ocorridas na relação do homem com o seu tempo e, assim, com a sua história, que passa a ser concebida uma obra em andamento, uma construção diária, dando ao sujeito a ilusão de total controle sobre o porvir, sobre o futuro. No âmago desses acontecimentos, a regularização de uma memória do dizer é de suma relevância para a instituição de novas práticas sociais, em consonância com as demandas de um novo tempo. Assim, buscamos uma melhor compreensão dos sentidos que se inscrevem no MA, tendo em vista os seus efeitos na regularização de uma memória sobre o Brasil, e o brasileiro, na atualidade. Para isso, trazemos a seguir alguns aspectos da sua historicidade, bem como um recorte analítico dos dizeres /sentidos que nele se inscrevem.

As transformações sociais advindas, em especial, da mundialização, promoveram uma ruptura a práticas anteriormente naturalizadas no seio social, resultando no que Hartog (2013) designa regime de historicidade moderno. Nessa ruptura, ainda segundo o autor, o sentido de modernização, atrelado ao futuro significado como progresso, dá lugar ao sentido de globalização, apontando, assim, não apenas para uma universalidade de culturas que se interpenetram a partir de um (ou mais) interesse(s) em comum, mas, sobretudo, para uma sociedade em construção contínua, na qual o futuro é construído, e modelado, a partir do agora. Para isso, a regularização de determinados sentidos, bem como a naturalização e circulação de determinadas práticas sociais, se fazem necessários. 


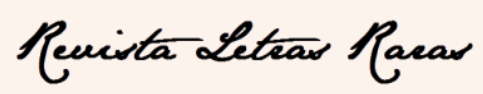

ISSN: $2317-2347$ - v. 8, n. 2 (2019)

Em especial na sociedade ocidental, como vimos afirmando, o museu ocupa um lugar relevante na reprodução/transformação de sentidos com vistas à regularização da memória no seio social, ou seja, um lugar em que se inscrevem e institucionalizam efeitos de memória. $\mathrm{Na}$ atualidade, mais que um lugar de mera transmissão de valores, o museu assume um papel preponderante na produção, constituição e circulação de sentidos na estrutura social, visto que produz diferentes modos de significação. Afinado com as práticas instituídas no novo tempo, contornado pela tecnologia digital, por certo modo de tecer rede de conexões e pelo sentido de um tempo futuro, o Museu do Amanhã possibilita ao sujeito diferentes modos de significação, advindos tanto da pluralidade de recursos tecnológicos disponíveis aos visitantes, promovendo uma maior interlocução entre os visitantes e o acervo, como pelas diferentes experiências (a serem) vivenciadas, sensoriais inclusive. Por essa via, o Museu do Amanhã traz em seu âmago as marcas do presentismo (HARTOG, 2017), fazendo emergir de seus acervos uma narrativa cuidadosamente selecionada, e contada a partir do aqui e do agora; uma história ordinária em permanente construção. Por meio da manipulação das informações que o visitante aparentemente escolhe ver, o museu proporciona ao sujeito, a ilusão do saber e do controle de um futuro que deseja apreender. Respondendo aos ditos anseios da nova sociedade ${ }^{4}$, o Museu do Amanhã (MA) foi inaugurado na cidade do Rio de Janeiro, em 2015, como parte do projeto designado chamado Porto Maravilha, a fim de fortalecer a identidade cultural e internacional da cidade do Rio de Janeiro. Com uma arquitetura futurística, o MA se debruça sobre a baía da Guanabara (Fig.1), imaginariamente sob a forma de uma bromélia - espécie nativa da América tropical com a possibilidade de abrir as suas folhas para os céus. Suas janelas guiam o olhar do espectador para o horizonte, direcionando o espectador para uma suposta continuidade entre a água do mar e a terra do continente.

Fig. 1 - Arquitetura futurística do Museu

\footnotetext{
4 Pelo termo "ditas demandas", propomos uma reflexão sobre um imaginário acerca do sujeito contemporâneo e seus anseios na atual sociedade, em uma desnaturalização desses sentidos aparentemente evidentes que são muitas vezes postos em circulação na esfera social. Consideramos que, inerente a esses dizeres está uma carga ideológica direcionando os sentidos a fim de convocar os sujeitos à tomada de posição condizente com os interesses da ordem ditada.
}

Todo o conteúdo da Revista Letras Raras está licenciado sob Creative Commons Atribuição 4.0 Internacional 


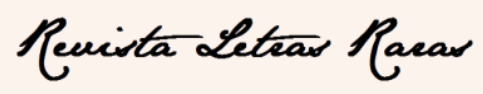

ISSN: 2317-2347 - v. 8, n. 2 (2019)

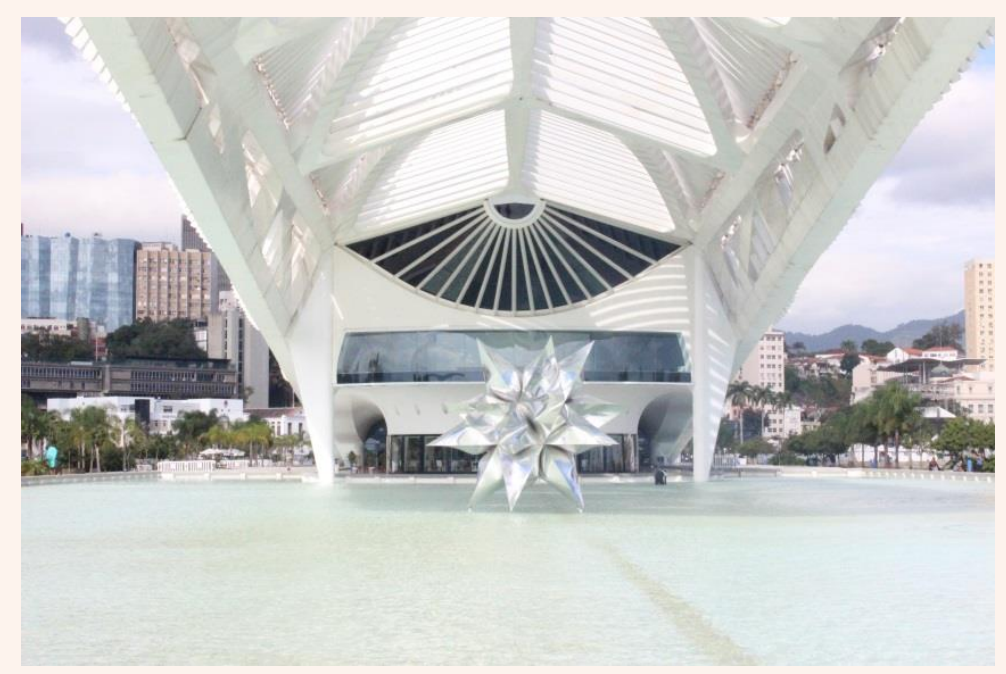

Fonte: Fotografia de Lucília Maria Abrahão e Sousa

Ainda com os olhos fitos no amanhã, o MA oferece a seu público uma experiência sensorial com o Cosmos, seção onde o visitante é levado à formação do planeta. Nela, logo à entrada, o globo terrestre suspenso (Fig. 2) capta a atenção do espectador para o movimento da terra, sendo direcionado às marcações de clima, fluxo de águas, correntes de ventos, posição em relação ao sol e à lua e indicações de solo atualizados em tempo real. Isso já produz o efeito de um presente completamente esgotado pela tecnologia, ou seja, é possível ver, sob efeitos de luz, sombra, cores e movimento, a des-referencialização espacial, produzindo um ilusório distanciamento da Terra, em que o visitante é tomado a ver o seu espaço no presente como se não estivesse dentro dele, nele, vivendo em suas terras. O presente do terráqueo como se fosse um outro distante na galáxia a navegar de fora do dentro de onde vive: esse nos parece ser um ponto importante que o MA coloca em movimento, a tecnologia a produzir o efeito de uma atualidade capaz de, mais adiante, de dirigir o futuro.

Fig. 2 - Globo terrestre 


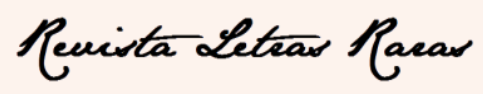

ISSN: 2317-2347 - v. 8, n. 2 (2019)

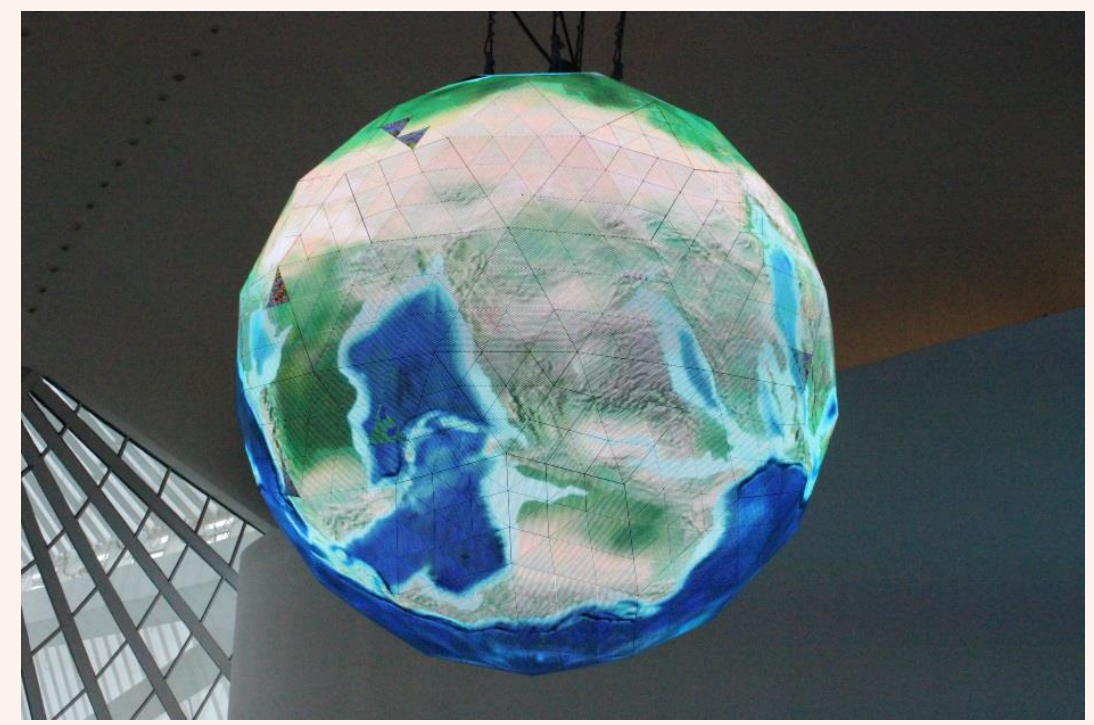

Fonte: Fotografia de Lucília Maria Abrahão e Sousa

Uma das especificidades das tecnologias digitais na atualidade, segundo Lévy (1996), é a possibilidade de virtualização, possibilitando ao sujeito uma desterritorialização do seu espaço-temporal de referência. Embora os sujeitos não estejam totalmente alheios a essa relação, de acordo com o autor, o espaço virtual promove uma espécie de desengate os separa do espaço físico ou geográfico ordinário e da temporalidade do relógio e do calendário, produzindo efeitos nos sujeitos discursivos contemporâneos, e no nosso caso nos sujeitos visitantes e leitores do MA. Efeitos muitas vezes resultantes de um processo de identificação do sujeito aos dizeres que se inscrevem nos acervos cuidadosamente selecionados, e expostos, a fim de produzir um efeito de unidade e linearidade dos sentidos que ali se materializam. Por um jogo de imagens, no qual implicam as regras de projeção e antecipação do sujeito em relação àqueles dizeres/sentidos (PÊCHEUX, 1969), regulariza-se uma memória do dizer condizente com os interesses de instituições mantenedoras e seus gestores sob a ilusão de completude que ali se constitui.

E é a jogar com a (in)completude do sujeito, ávido por significar (PÊCHEUX, 1988) que o MA convoca o visitante a desbravar caminhos (sobre)determinados em busca dos sentidos ali inscritos, que se materializam em uma exposição permanente acerca da importância da sustentabilidade para o bem-estar mundial. Sem placas indicativas, sujeitos e sentidos são direcionados ao lugar do científico e do informativo, produzindo uma ilusão de autonomia, de controle do sujeito, na escolha ilusoriamente 


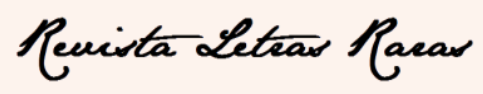

ISSN: $2317-2347$ - v. 8, n. 2 (2019)

livre do caminho a percorrer. Nesses termos, o amanhã tem muitos caminhos e o visitante pode vagar a esmo, sem coordenadas, olhando tanto pra fora do museu que é inteiramente vazado por vidros quanto pra dentro nas paredes, máquinas, instalações marcadas pela exposição tecnológica. Os caminhos se abrem e, afinados às ditas demandas do século XXI, conduzem os sujeitos aos sentidos de inovação que perdura durante toda a exposição, do novo de novo, rumo ao futuro que tem como seu ponto fixo o presente. O presente quantificado, o presente animado por imagens e sons, o presente documentado por números, o presente marcado por jogos digitais, presente este tão investigado e tornado repetível que se dá a ver também nas conseqüências de um futuro presente, que se materializa, no MA. Trazemos aqui a representação de um cogumelo de Hiroshima (Fig. 3) para marcar tal funcionamento; em uma exposição central denominada Amanhãs, o cogumelo de Hiroshima reproduz possíveis efeitos das ações dos sujeitos contemporâneos no meio ambiente e suas implicações às gerações vindouras. Em sua forma plural Amanhãs, os dizeres ali materializados em imagens e sons direcionam os sentidos, mais uma vez, para a suposta liberdade de escolha do sujeito em relação ao seu futuro, ou ao desejo de futuro da humanidade.

Fig. 3 - Cogumelo de Hiroshima

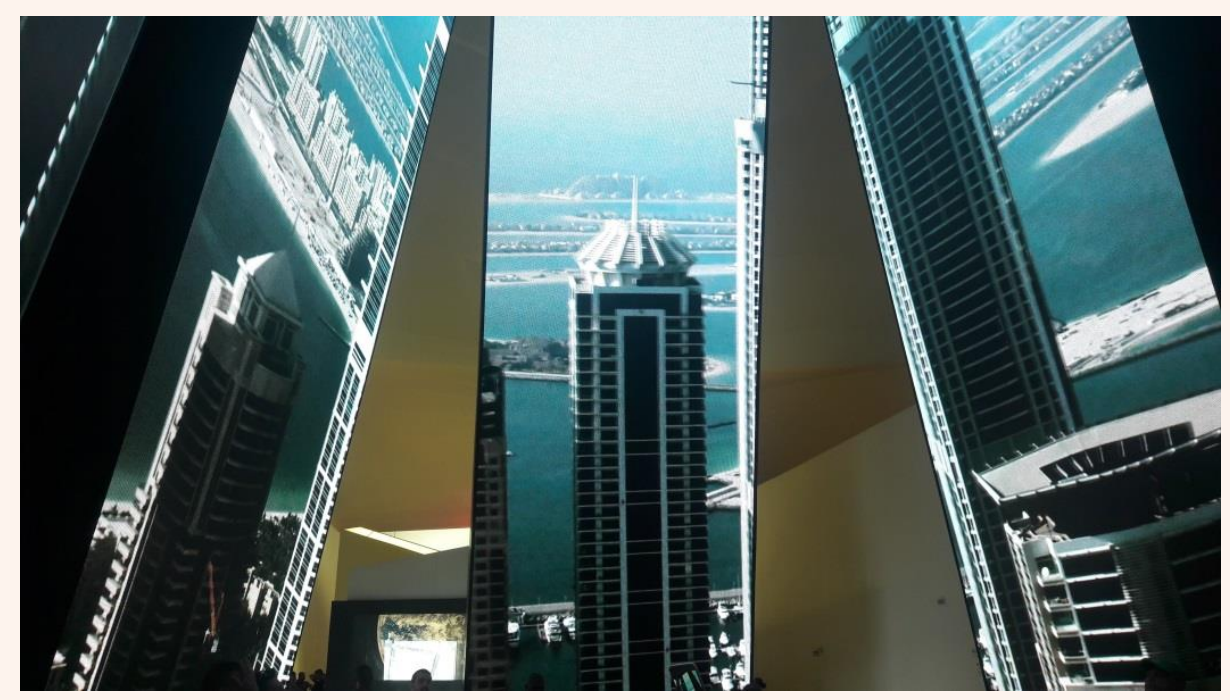

Fonte: Fotografia de Lucília Maria Abrahão e Sousa

Ao pensar nos possíveis danos para o Ecossistema, o MA direciona os sentidos para uma sociedade globalizada, cujos sujeitos se inscrevem numa identidade 


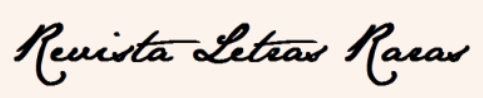

ISSN: $2317-2347$ - v. 8, n. 2 (2019)

globalizada, unificada; corroborando, assim, os dizeres relativamente estabilizados acerca de uma aldeia global e, por sua vez, uma cultura universal. Sentidos esses materializados também em um labirinto de fotos de diferentes povos replicados infinitamente por um jogo de espelhos (Fig. 4). Embora a diversidade cultural na qual a humanidade se pauta na atualidade esteja, de certa forma, ali materializada, podemos observar que as especificidades inerentes a cada povo, cada comunidade ali representada se esvanecem no jogo de luzes, sons e espelhos, dando lugar a uma aparente homogênea "massa de indivíduos", produzindo assim um apagamento da historicidade inerente à formação de cada nação.

Fig. 4 - Jogo de espelhos

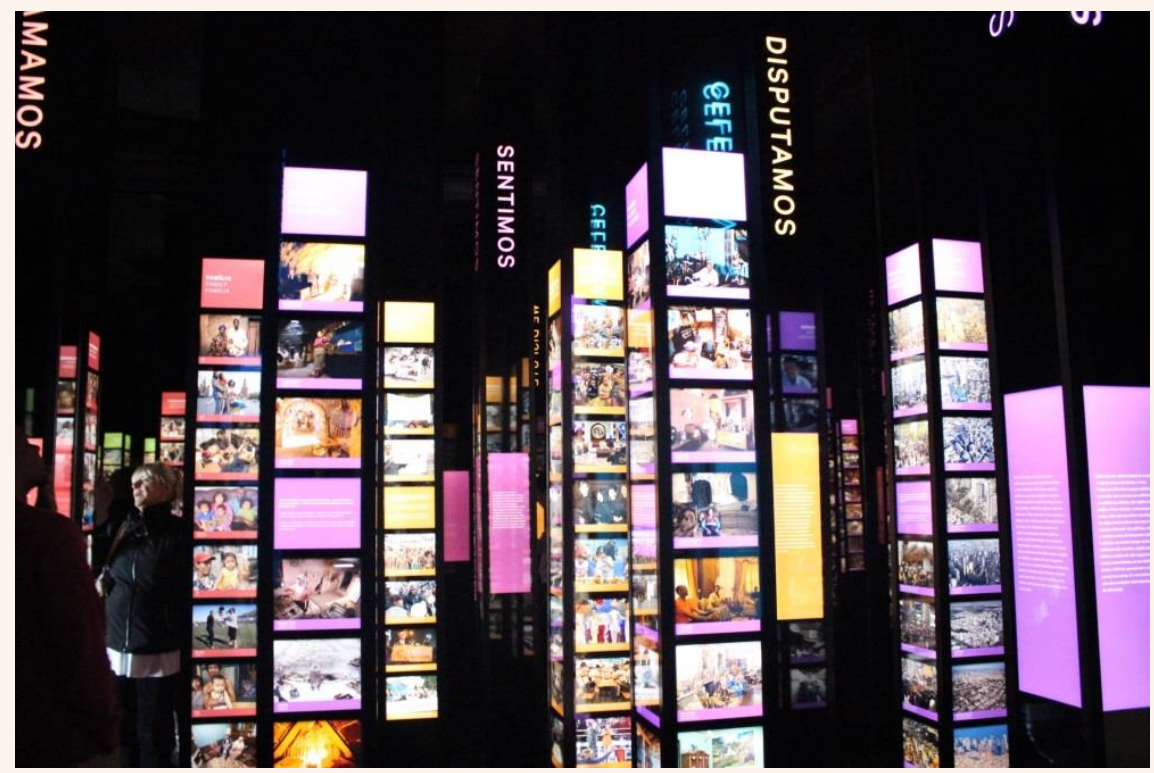

Fonte: Fotografia de Lucília Maria Abrahão e Sousa

No que tange ao Brasil, a historicidade de nossa formação social se faz presente na sessão Nós, representada por uma peça física que traz à memória uma oca, como habitação indígena. É interessante observar como o efeito de oca passa aqui a ser modificado pela tecnologia dada pela iluminação em cores e pelos microfones com sons: é uma oca tecnológica que não guarda relação visual de parentesco com as aldeias indígenas brasileiras, pois não traz os materiais da floresta, nem tem a configuração fechada de habitação, nem apresenta as redes e esteiras tão frequentes nas aldeias. O que se marca de oca é o nome, quase oco, diga-se de passagem. Uma oca contemporânea sem vestígios de índios, sem a língua deles, os alimentos e as práticas culturais que os

Todo o conteúdo da Revista Letras Raras está licenciado sob Creative Commons Atribuição 4.0 Internacional 


\section{Reuista Leteas Racar}

ISSN: $2317-2347$ - v. 8, n. 2 (2019)

constituem: silenciam-se aqui os povos das florestas, sua voz e seus saberes e, em lugar deles, uma obra de arte se instala e inscreve, na relação da história com a língua, outro modo de dizer e fazer ver uma oca (Fig. 5 e 6). É aquela pelo que a memória sustenta e permite retomar, mas é outra completamente diversa pelo que se apresenta.

Fig. 5 - Representação de uma oca

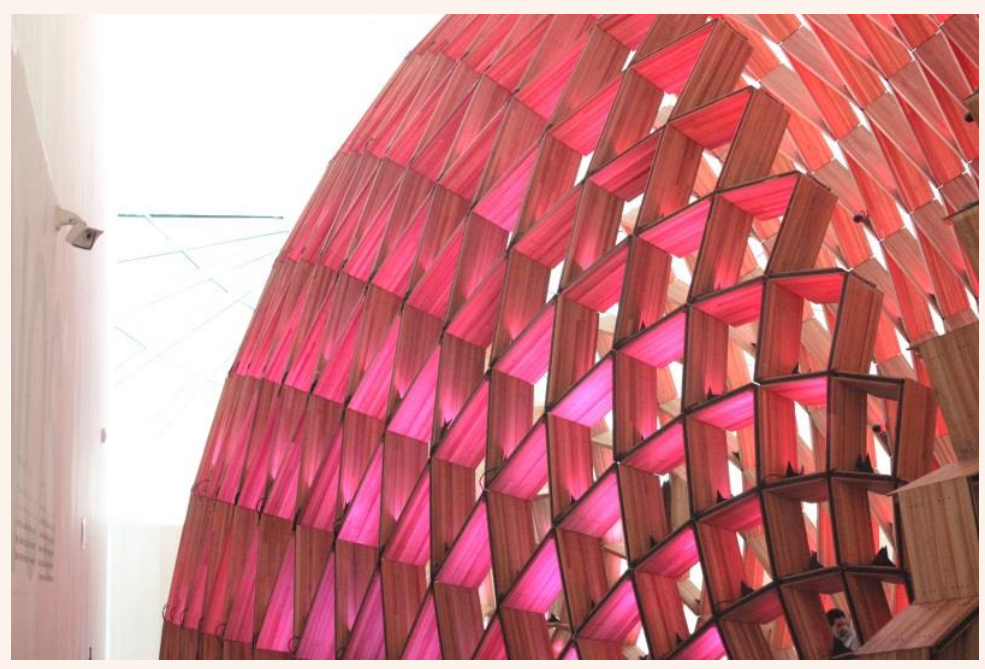

Fonte: Fotografia de Lucília Maria Abrahão e Sousa

Fig. 6 - Interior da oca

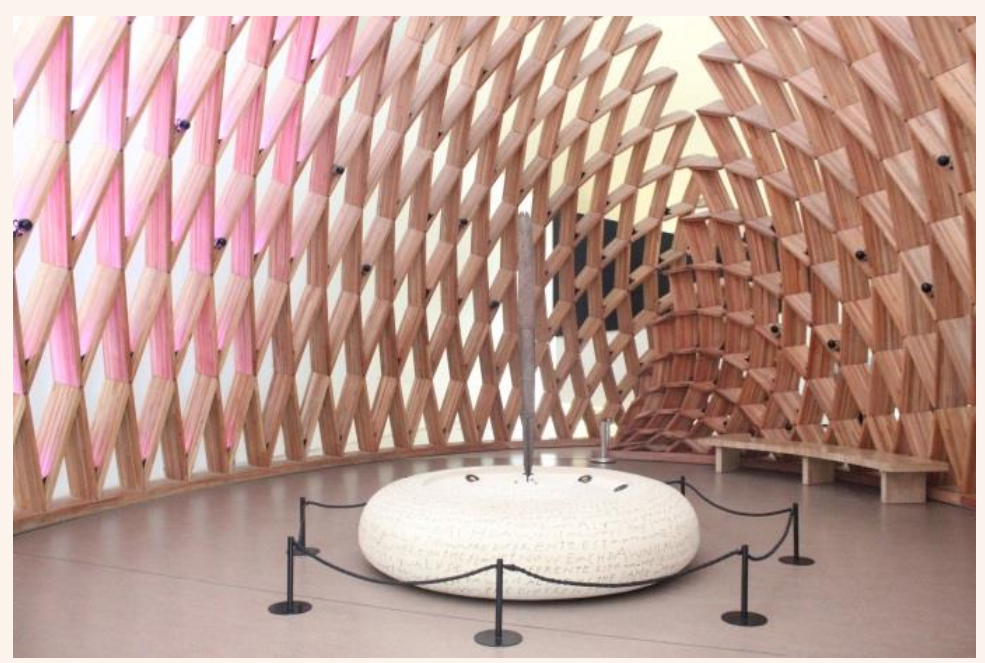

Fonte: Fotografia de Lucília Maria Abrahão e Sousa

Como podemos observar a seguir, a oca se materializa em uma peça feita em madeira cuidadosamente trabalhada, cujo colorido traz um ar de elegância à obra de arte. $\mathrm{Na}$ disputa ideológica pela estabilização de uma memória do dizer, segundo 


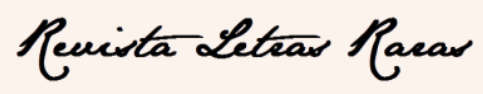

ISSN: 2317-2347 - v. 8, n. 2 (2019)

Orlandi (2001), não apenas os já-ditos significam, operando na reprodução de determinados sentidos a serem regularizados, mas também os não-ditos se marcam no dizer sob a forma de silenciamento, produzindo os seus efeitos. Por meio dessa obra de arte com a representação de uma elegante moradia indígena, observamos o silenciamento da simplicidade de um estilo de vida frugal dos nativos, que habitavam (e habitam) em nossas terras. Ao adentrarmos, o silenciamento aos indígenas também se faz materializa na ausência de um representante, ou elementos que a eles façam menção no seu interior. Ali, a possibilidade virtualização, propiciada pelos recursos digitais largamente utilizados no MA - que poderia dar uma nova dimensão ao saber do brasileiro sobre sua identidade - também não comparece.

Nessa mesma sessão, Nós, a historicidade inerente à formação do Brasil e do povo brasileiro é silenciada, ainda, por um apagamento da matriz africana, inerente à construção das identidades do brasileiro em suas diferentes realidades. Assim, pelo jogo polissêmico constitutivo da língua (ORLANDI, 2001), o termo nós [eu e você(s)] direciona os sentidos também para os nós, enquanto amarras que nos remete às questões identitárias do brasileiro e toda a heterogeneidade social, cultural e linguística na e pela qual somos formados. "Nós" também implica um todo, um coletivo que toma como naturalmente iguais todos os habitantes do planeta, mais ainda, um coletivo universal e genérico que sabota as diferenças e desigualdades, que silencia o diverso e faz parecer evidente que existiria uma equidade de direitos entre todos os povos da terra, entre todos os habitantes do mundo e entre todas as partes do globo. Sob o discurso da globalização, o MA direciona os sentidos a um apagamento das especificidades de cada povo, conferindo um efeito de homogeneização aos sujeitos discursivos.

Numa relação intrínseca entre memória e esquecimento, ainda segundo Orlandi (2007), o silenciamento pode decorrer das escolhas das palavras, e dos sentidos, a serem lembrados, enquanto outros são esquecidos a depender dos interesses da ordem vigente. Sendo assim, o conhecimento das condições sócio-histórico-ideológicas nos quais os discursos se constituem é de suma relevância para a compreensão dos sentidos neles se inscrevem. Idealizado como um ícone cultural da cidade, a sua inauguração culmina com as organizações para os eventos internacionais sediados no país, Olimpíada Rio 2016 e Copa do Mundo 2018, visando à recepção do público desportista e admiradores do esporte. Período em que, ancorado num suposto milagre econômico, os discursos 


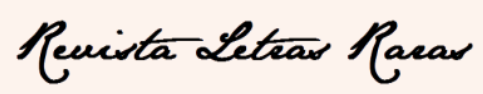

ISSN: $2317-2347$ - v. 8, n. 2 (2019)

acerca de modernização e progresso são retomados e parecem fundir-se com o sentido de globalização, convocando os sujeitos discursivos, em especial os brasileiros, a uma tomada de posição rumo a sua inserção na nova sociedade comumente discursivizada aldeia global com vistas a uma cultura unificada.

\section{Considerações finais}

O museu se caracteriza, desde a sua constituição, por um espaço heterogêneo marcado por uma divisão política; um espaço regulador/normatizador de uma memória, em uma determinada conjuntura sócio-política e econômica, colocando em cena uma hierarquização dos sentidos que se materializam por meio dos acervos nele dispostos.

A partir das análises apresentadas, observamos que afinado com as demandas dos novos tempos, o MA convoca o futuro, sendo construído a partir do presente, direcionando os sentidos para um presentismo, como um dos sintomas das transformações sociais.

O caráter predominantemente sensorial, a partir da interatividade por excelência, advinda do acervo digital e dos jogos ali presentes, promove o apagamento das relações de poder que nele se inscrevem. O suposto livre acesso, aparentemente sem pistas a serem seguidas, proporcionam nos sujeitos discursivos a ilusão de livre escolha do caminho a percorrer, imputando-lhes também a responsabilidade de sua tomada de posição. Sob a forma do lúdico, os recursos digitais ali disponíveis buscam privilegiar determinados sentidos a que se quer regularizar no seio social, enquanto as obras materiais produzem um efeito estético, mais que informativo dos sentidos a que se quer esquecer, ou até mesmo apagar.

Nesse contexto, por meio de uma exacerbação do presente, os dizeres que ali se inscrevem direcionam os sentidos para uma memória do dizer sobre o sujeito contemporâneo, em consonância com uma identidade globalizada e uma cultura universal por meio de uma homogeneização dos sentidos, e dos sujeitos na atualidade. Debruçado sobre uma paisagem inspiradora, o MA promove, assim, a instauração de novas práticas sociais firmadas em um ideal de povo e representação de sociedade, em que pese o apagamento da historicidade inerente à formação do país. 


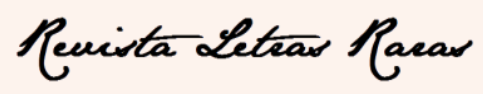

ISSN: 2317-2347 - v. 8, n. 2 (2019)

Direcionados para uma ilusão de felicidade plena, tais dizeres/sentidos estão pautados nas bases da sociedade capitalista, cujas práticas se inscrevem numa cultura de dominação e exploração, condizentes com os interesses do Mercado, colocando em jogo as relações identitárias do brasileiro e o seu país. E, assim, como uma obra presentista, o Museu do Amanhã vive um paradoxo com o seu passado, tendo como um dos seus efeitos cortes de verbas em instituições culturais tradicionais, em consonância com os novos tempos.

\section{REFERÊNCIAS}

ALTHUSSER, L. Ideologia e Aparelhos ideológicos do Estado. Lisboa: Presença, 1970.

CARLAN, C. U. Museums and Historical Heritage: a complex relationship. História, São Paulo, v.27, n.2, p.75-88, 2008.

HARTOG, F. Crer em História. Belo Horizonte: Autêntica, 2017.

HARTOG, F. Regimes de historicidade: presentismo e experiências do tempo. Belo Horizonte: Autêntica, 2013.

INSTITUTO DO PATRIMÔNIO HISTÓRICO E ARTÍSTICO NACIONAL. Cadastro Nacional de Museus. Disponível em: <portal.iphan.gov.br/files/questionario_cadastro_nacional_de_museus.doc>. Acesso em 6 set 2018 .

LACAN, J. (1958-1959). O Seminário, Livro 6: O desejo e sua interpretação. Rio de Janeiro: Jorge Zahar, 1985.

LÉVY, P. O que é o virtual? São Paulo: Ed. 34, 1996.

MARIANI, B. C. S. Sujeitos e discursos contemporâneos. In: INDURSKY, F; LEANDRO FERREIRA, M.C.; MITIMMAN, S. (orgs). $O$ discurso na contemporaneidade: materialidades e fronteiras. São Carlos: Claraluz, 2009.

ORLANDI, E. P. As formas do silêncio no movimento dos sentidos. Campinas: Editora da Unicamp, 2007.

ORLANDI, E. P. A linguagem e seu funcionamento: as formas do discurso. Campinas: Pontes, 2006.

ORLANDI, E. P. Discurso e texto: formulação e circulação dos sentidos. Campinas: Pontes, 2001.

PÊCHEUX, M. [1982]. Ler o arquivo hoje. In: ORLANDI, E. P. (Org.). Gestos de leitura. Campinas: Editora da Unicamp, 1997.

PÊCHEUX, M. Análise automática do discurso (AAD-69). In: GADET, F.; HAK, T. (orgs.). Por uma análise automática do discurso. Campinas: Editora da Unicamp, 1997. 


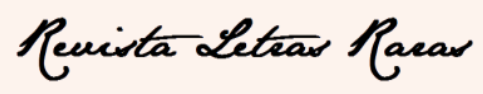

ISSN: 2317-2347 - v. 8, n. 2 (2019)

PÊCHEUX, M. Semântica e discurso: uma crítica à afirmação do óbvio. Campinas: Editora da Unicamp, 1988.

PÊCHEUX, M. Papel da memória. In: ACHARD, P. (org.). Papel da memória. Campinas: Pontes, 1999.

ROMÃO, L. M. S. Exposições do Museu da Língua Portuguesa: arquivo e acontecimento e (m) discurso. São Carlos: Pedro \& João Editores, 2011.

ROSARIO, C. C. do. O lugar mítico da memória. Morpheus. Revista Eletrônica de Ciências Humanas, Rio de Janeiro, v. 1, n. 1, 2002.

SOUSA, L. M. A.; GARCIA, D.; FARIA, D. Eu curto, tu curtes, ele (não me) curte: notas sobre o funcionamento do arquivo no Face. RUA, Campinas, v.23, p. 221-241, 2017.

SOUSA, L. M. A. De presença e ausência, trilhamentos discursivos em dois museus. In VENTURINI, M. C. Museus, arquivos e produção do conhecimento em (dis)curso. Campinas, Pontes, 2017.

VERNANT, J-P. Mito e pensamento entre os gregos. Rio de Janeiro: Paz e Terra, 1990.

ZOPPI-FONTANA, M. G. Arquivo jurídico e exterioridade. A construção do corpus discursivo e sua descrição/interpretação. In: GUIMARÃES, E. ; BRUM, M. (Orgs). Sentido e Memória. Campinas: Pontes, 2005.

Data de recebimento: 13/04/2019

Data de aceite: $31 / 05 / 2019$ 